\title{
NEW RADIOCARBON DATES FOR THE REED MAT FROM THE CAVE OF THE TREASURE, ISRAEL
}

\author{
Gerald E Aardsma \\ Aardsma Research \& Publishing, 412 N Mulberry, Loda, Illinois 60948-9651, USA
}

\begin{abstract}
Modern radiocarbon dates were procured for the Cave of the Treasure, Israel reed mat at the University of Arizona accelerator mass spectrometry (AMS) laboratory in late 1999 and early 2000. Three samples from various locations on the mat were dated. One of these samples was dated twice, and another was dated three times, yielding a total of six new radiocarbon dates on the mat. The new ${ }^{14} \mathrm{C}$ dates overturn expectations of a late Chalcolithic, roughly $3500 \mathrm{BC}$, date for the origin of the mat. It is suggested that the mat may not have been of common use but may rather have been a religious heirloom with a history stretching back into the early Chalcolithic.
\end{abstract}

\section{INTRODUCTION}

Progress in the field of biblical chronology over the past decade (Aardsma 1999) has prompted new interest in the absolute chronology of the archaeological time periods within the land of Israel. One target of current interest stemming from this field is the proper calendar date of the terminal Chalcolithic. The present involvement with the Cave of the Treasure mat results from this interest.

It is now beyond reasonable doubt that traditional biblical chronology has inadvertently foreshortened the dates of biblical events from Genesis through Judges by a full millennium (Aardsma 1993). The foreshortening appears to result from a scribal copy error in a single number in a very early manuscript of 1 Kings. Restoration of this biblical number yields a quantitatively precise correction of traditional biblical chronology. This correction moves the chronology of the biblical narrative from Genesis through Judges back exactly 1000 years relative to traditional expectations.

A realignment of several key biblical events relative to the secular history of the land of Israel resulting from this correction is shown in the first three columns of Figure 1. While the dates of the monarchical and later biblical periods remain unchanged, the dates of the exodus, conquest, and prior events all fall exactly 1000 years earlier than traditionally calculated, as shown by the dashed lines in Figure 1. This realignment has successfully explained why nothing suitable to the biblical narrative of the exodus and conquest has ever been found in the secular history and archaeology of the second millennium. These events do not belong to the second millennium, but rather to the third millennium, where they immediately find a convincingly suitable secular setting.

Interest in the calendar date of the terminal Chalcolithic stems from the observation (Figure 1) that the corrected biblical chronology places Noah's flood in apparent temporal coincidence with the terminal Chalcolithic. Noah's flood is depicted in the Bible as a catastrophe of unusual magnitude and large geographical extent, which left only a handful of survivors. Strikingly, a comprehensive survey of archaeological data for the Chalcolithic in Israel leads modern archaeologists to conclude, independent of all biblical considerations, that: "The impression is created of a sudden end of the period as a result of a catastrophe of some sort, either natural or inflicted by man..." (Gonen 1992). In point of fact, the termination of the Chalcolithic is archaeologically unique in Israel. It appears as an abrupt extinction of a sophisticated civilization, and the succeeding period, the Early Bronze Age, marks a new beginning in which civilization appears to have started again "from scratch" (Gonen 1992). Nothing comparable to this is ever seen again in the entire subsequent archaeological record of the land of Israel. The uniqueness of the Chalcolithic termination is perhaps most easily illustrated by the fact that the vast majority of Chalcolithic sites are single-period sites-when they come to an end they are not rebuilt—in contrast to Early Bronze sites, many of which show continued

(C) 2001 by the Arizona Board of Regents on behalf of the University of Arizona

Near East Chronology: Archaeology and Environment. RADIOCARBON, Vol 43, Nr 3, 2001, p 1247-1254

Proceedings of the 17 th International ${ }^{14} \mathrm{C}$ Conference, edited by $\mathrm{H}$ J Bruins, I Carmi, and E Boaretto 


\begin{tabular}{|c|c|c|c|c|}
\hline B.C. & Bible & Israel & Bible & Cave of Treas. mat \\
\hline & traditional & archaeological & modern & radiocarbon \\
\hline 600 & - - fall of Jerusalem --. & & ..- fall of Jerusalem - & \\
\hline 700 & & & . $\ldots \ldots \ldots \ldots \ldots$ & \\
\hline 800 & n & IRON II & $\ldots \ldots \ldots \ldots$ & \\
\hline 900 & & & $\cdots$ & \\
\hline 1000 & - David begins to reign - & & - David begins to reign - & \\
\hline 1100 & $\ldots \ldots \ldots \ldots \ldots \ldots \ldots$ & $\cdots \operatorname{IRON} \cdot \mathbf{I} \cdot$ & $\cdots=$ birth of Samuel - . & \\
\hline 1200 & $\cdots$ & & & \\
\hline 1300 & $\ldots \ldots \ldots \ldots \ldots \ldots$ & LATE BRONZE II- & $\cdots \cdot$ & \\
\hline $\begin{array}{l}1400 \\
1500\end{array}$ & Conquest begins $-\gamma$ & LATE. BRONZE.I . & & \\
\hline 1600 & & MDDL F PBONZF & $\cdots$ & \\
\hline 1700 & & IMIYQLE BRULZE & $\ldots$ & \\
\hline 1800 & ................. & & $\ldots$ & \\
\hline $\begin{array}{r}1900 \\
2000\end{array}$ & 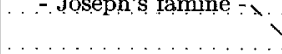 & MLDLE BRONZE I. & - death of Samson - & \\
\hline 2100 & $\ldots \ldots \ldots$ & $\therefore$ 's & & \\
\hline 2200 & $\ldots \ldots \ldots$ & EARLY BRONZE IV & & \\
\hline 2300 & $\ldots$ & or INTER. BRONZE & & \\
\hline 2400 & $\cdots$ & ' ' & $\therefore$ Conquest begins - & \\
\hline 2500 & - Noah's Flood - & EARLY BRONZE III & & \\
\hline $\begin{array}{l}2000 \\
2700\end{array}$ & & $\ldots \ldots$ & & \\
\hline 2800 & ... & EARLY BRONZE II & & \\
\hline 2900 & $\cdots$ & & ' - Joseph's famine -.. & \\
\hline 3000 & & EARLY BRONZE I & $\ldots$ & \\
\hline $\begin{array}{l}3100 \\
3200\end{array}$ & $\cdots$ & & ........ & \\
\hline 3300 & $\cdots$ & & $\cdots \cdot$ & $3 \ldots$ \\
\hline 3400 & & & $\ldots$ & \\
\hline 3500 & $\cdots \cdot \cdot$ & & '. - Noah's Flood - & $i$ \\
\hline 3600 & $\cdots$ & & & \\
\hline $\begin{array}{l}3700 \\
3800\end{array}$ & & & ${ }^{\cdots} \ldots \ldots \ldots \ldots$ & \\
\hline 3900 & .... & & $\cdots \cdots$ & \\
\hline 4000 & .. & & $\ldots \ldots \ldots \ldots$ & \\
\hline 4100 & $\ldots$ & & $\ldots \ldots \ldots \ldots$ & …… 目 $5 \ldots$ \\
\hline 4200 & $\cdots$ & CHALCOLITHIC & & $\cdots_{2}$ \\
\hline $\begin{array}{l}4500 \\
4400\end{array}$ & & & & G \\
\hline 4500 & & & & $\cdots \cdots$ \\
\hline 4600 & & & $\cdots$ & 只 \\
\hline 4700 & & & & $\ldots$ \\
\hline 4800 & & & $\cdots \cdots$ & $\ldots \ldots \ldots \ldots$ \\
\hline 4900 & $\cdots \cdot$ & & $\ldots .$. & \\
\hline 5000 & & & & $\cdots \cdots \cdots$ \\
\hline 5100 & & & & \\
\hline 5200 & & NEOLI & & \\
\hline
\end{tabular}

Figure 1 Time chart showing all available ${ }^{14} \mathrm{C}$ dates on the Cave of the Treasure mat relative to traditional and modern biblical chronology, and also relative to an archaeological chronology of the land of Israel. The numbers above the radiocarbon date ranges correspond to the sample numbers in Table 1. Black bars show one sigma, and open bars two sigma ranges. Calibration was accomplished using the 1998 atmospheric decadal dataset of CALIB 4.0 (Stuiver and Reimer 1993). 
occupation and reoccupation even into modern times. These observations lead to the hypothesis that the biblical narrative of Noah's flood and the archaeological reconstruction of the terminal Chalcolithic are two perspectives of one and the same historical event.

The robustness of the apparent synchronization between the modern biblical date of Noah's flood and the secular date of the end of the Chalcolithic is clearly of interest in this context. The date of Noah's flood calculated on the basis of modern (corrected) biblical chronology has a high precision, if still uncertain accuracy. It is $3520 \pm 21 \mathrm{BC}$. The secular date for the end of the Chalcolithic has a much lower precision. Modern archaeological estimates generally range between about 3000 and 3600 BC. The New Encyclopedia of Archaeological Excavations in the Holy Lands (Stern 1993) adopts a value of $3300 \mathrm{BC}$, for example, while Gonen (1992) says a corpus of ${ }^{14} \mathrm{C}$ dates from Chalcolithic sites in Israel implies "about 3600 B.C.E." One would obviously like to improve the precision of the date of the terminal Chalcolithic. This leads to an interest in the Cave of the Treasure mat.

The Cave of the Treasure mat was discovered by an archaeological team working under the direction of Pessah Bar-Adon in 1961 (Bar-Adon 1980). Its stratigraphic context was clearly Chalcolithic. The treasure of mainly copper objects found together with the mat also pointed to a Chalcolithic date for the mat.

Several observations suggested a late Chalcolithic date for the burial of the mat. First, the mat was found buried beneath a thick Chalcolithic deposit within the Cave of the Treasure. This deposit had been dug through to secure a hiding place for the mat and its associated treasure. The depth of deposit dug through implied that the mat was not hidden near the beginning of the Chalcolithic.

Second, the copper objects found in association with the mat displayed an advanced technological ability, which seemed most appropriate within a late Chalcolithic setting (Bar-Adon 1980).

Third, the whole setting of the burial of the treasure seemed to suggest an imminent calamity of some kind. The treasure was obviously buried in haste. After its burial, Chalcolithic occupation of the Cave of the Treasure ceased. The fact that the Chalcolithic closes at many other sites in Israel with some sort of calamity leading to apparent abandonment suggested that the mat may have been buried near the end of the Chalcolithic period (Bar-Adon 1980).

Since a mat made of reeds may be expected to have a short service life in ordinary usage, the foregoing observations implying a terminal Chalcolithic date for the burial of the mat also suggested that the mat itself may have originated very near the end of the Chalcolithic period in Israel. ${ }^{14} \mathrm{C}$ measurements made on the mat and its associated objects in the early 1960s seemed to corroborate this expectation (Table 1). Three of four ${ }^{14} \mathrm{C}$ dates made at that time, when calibrated using tree-rings, grouped near $3500 \mathrm{BC}$, a reasonable date for the terminal Chalcolithic.

But these early dates were not altogether satisfactory. First, measurement techniques were crude compared to modern-day standards when these dates were obtained 35 or more years ago. It was clear that a much more precise date could be obtained on the mat using modern ${ }^{14} \mathrm{C}$ dating technology and methods.

Second, there was not complete harmony between the three ${ }^{14} \mathrm{C}$ dates $(1,2$, and 3 of Table 1$)$ which had been made on the mat itself. The three dates had been obtained by three separate labs. Two of the dates were in agreement ( 1 and 3), but the third (2) was some 500 to 600 years older. (A fourth date, sample \#0 in Table 1, not on the mat itself but rather on wood found in association with the mat, harmonized with the two mat dates that were in agreement. This gave three ${ }^{14} \mathrm{C}$ dates in agreement and one significantly different.) 
Table 1 All radiocarbon measurements presently available on the Cave of the Treasure mat

\begin{tabular}{|c|c|c|c|c|c|c|c|c|}
\hline sample \# & lab \# & ARP \# & material & provenience & measured & ${ }^{14} \mathrm{C}$ age $\mathrm{BP}$ & $\delta^{13} \mathbf{C}$ & references \\
\hline 0 & I-353 & - & wood & copper standards & 1961 & $4760 \pm 120^{b}$ & not measured ${ }^{d}$ & Bar-Adon, 199 \\
\hline 1 & $\mathrm{I}-285$ & - & mat fragment & outer edge of mat & 1961 & $4780 \pm 100^{b}$ & not measured ${ }^{d}$ & Bar-Adon, 199\&216 \\
\hline 2 & BM-140 & - & mat fragment & inner portion of mat & 1963 & $5390 \pm 78^{b, c}$ & not measured & $\begin{array}{l}\text { Bar-Adon, 199\&216 } \\
\text { Radiocarbon 10:4 }\end{array}$ \\
\hline 3 & $\mathrm{~W}-1341^{a}$ & - & mat fragment & outer edge of mat & 1964 & $4880 \pm 250^{b}$ & not measured & $\begin{array}{l}\text { Bar-Adon, 199\&216 } \\
\text { Radiocarbon } 7: 396-397\end{array}$ \\
\hline 4 & AA35141 & ARP-201a & mat fragment & unknown & 1999 & $5375 \pm 55$ & -9.4 & \\
\hline 5 & AA35141 & ARP-201b & mat fragment & unknown & 2000 & $5475 \pm 60$ & -8.9 & \\
\hline 6 & AA37205 & ARP-212 & straw twine & see Figure 2 & 2000 & $5520 \pm 50$ & -8.5 & \\
\hline 7 & AA37206 & ARP-213a & reeds & see Figure 2 & 2000 & $6020 \pm 55$ & -10.1 & \\
\hline 8 & AA37206 & ARP-213b & reeds & see Figure 2 & 2000 & $5724 \pm 47$ & -11.3 & \\
\hline 9 & AA37206 & ARP-213c & reeds & see Figure 2 & 2000 & $6020 \pm 60$ & -10.6 & \\
\hline
\end{tabular}

a. Bar-Adon designates this sample "WR-1341".

b. Not corrected for isotope fractionation.

c. The original measurement uncertainty published is \pm 150 . This included contributions of \pm 80 years for possible isotopic fractionation effects and \pm 100 years for de Vries-effects (Radiocarbon 10:1). Thus the actual counting imprecision is \pm 78 years.

d. Personal communication with Jim Buckley of Teledyne (formerly Isotopes Inc.) 97/11/17. 
Third, these early ${ }^{14} \mathrm{C}$ determinations had not been corrected for isotope fractionation $\left(\delta^{13} \mathrm{C}\right.$ had not been measured), introducing the possibility of inaccuracies of several centuries in the reported dates.

\section{SAMPLES}

Three samples were procured from the mat and dated using accelerator mass spectrometry (AMS) in late 1999 and early 2000. The first, ARP-201, was a fragment of the mat that was not part of the permanent museum display. Only a portion of the ARP-201 sample was needed for the initial AMS measurement. Because this measurement yielded a significantly older date than had been expected, the remaining portion of ARP-201 was dated to check for inadvertent experimental error. These two determinations gave results in agreement within statistical counting uncertainties. Normally the two determinations would be averaged to yield a single date for the sample. This has not been done in the present case because the sample was not homogenized before analysis (i.e., it consisted of individual pieces of plant remains) and there now seems significant probability that the reeds of the mat are not all of the same age (see below). The two portions of the ARP-201 sample are designated ARP-201a and ARP-201b in Table 1; they share a common AMS lab number, AA35141.

The remaining two samples were taken from the mat at the locations shown in Figure 2. ARP-212 was composed entirely of the straw twine used as weft. ARP-213 was entirely of reeds (also not homogenized). The AMS result for ARP-213 was checked twice, yielding a total of three dates. The three different portions of the bulk ARP-213 sample used are designated ARP-213a, ARP-213b, and ARP-213c.

\section{RESULTS}

All available ${ }^{14} \mathrm{C}$ dates on the mat are shown in Table 1, together with one date on the piece of wood mentioned above. The nine calibrated mat dates resulting from these data are shown in the final column of Figure 1.

\section{DISCUSSION}

Once $\delta^{13} \mathrm{C}$ had been measured on the ARP samples it was possible to correct the three 1960s dates on the mat for isotope fractionation using the average measured $\delta^{13} \mathrm{C}$ value of $-9.8 \pm 1.1$. This correction moved the calibrated dates for these mat samples (1 through 3 in Figure 1) back several centuries relative to their uncorrected calibrated dates. (The date ranges shown for samples 1, 2, and 3 in Figure 1 include this correction for isotope fractionation.) This removed the initial apparent support of samples 1 and 3 for a late Chalcolithic date for the origin of the mat.

The six modern AMS dates (4 through 9) also fail to support a late Chalcolithic date for the origin of the mat. Thus, the principal conclusion of interest to the main purpose of this work is that the Cave of the Treasure mat is evidently not well suited to the problem of refining the date of the terminal Chalcolithic after all. This artifact now appears to have a much more ancient and complex history than has previously been assumed.

While this is the primary conclusion, so that in one sense we are done, the nine ${ }^{14} \mathrm{C}$ results on the mat (Figure 1) beg further discussion. In greatest need of discussion, from an experimental perspective, is the fact that they do not group around a single mean. Rather, they are spread out in at least three groups over a millennium or more. This large spread not only makes it impossible to assign a precise date of origin to the mat, it also seems to call into question radiocarbon's ability to date this object. In this regard, however, it is important to notice that measurement reproducibility has been demonstrated with discrete samples from this mat. ARP-201a (4 in Figure 1) and its check, ARP-201b (5), 


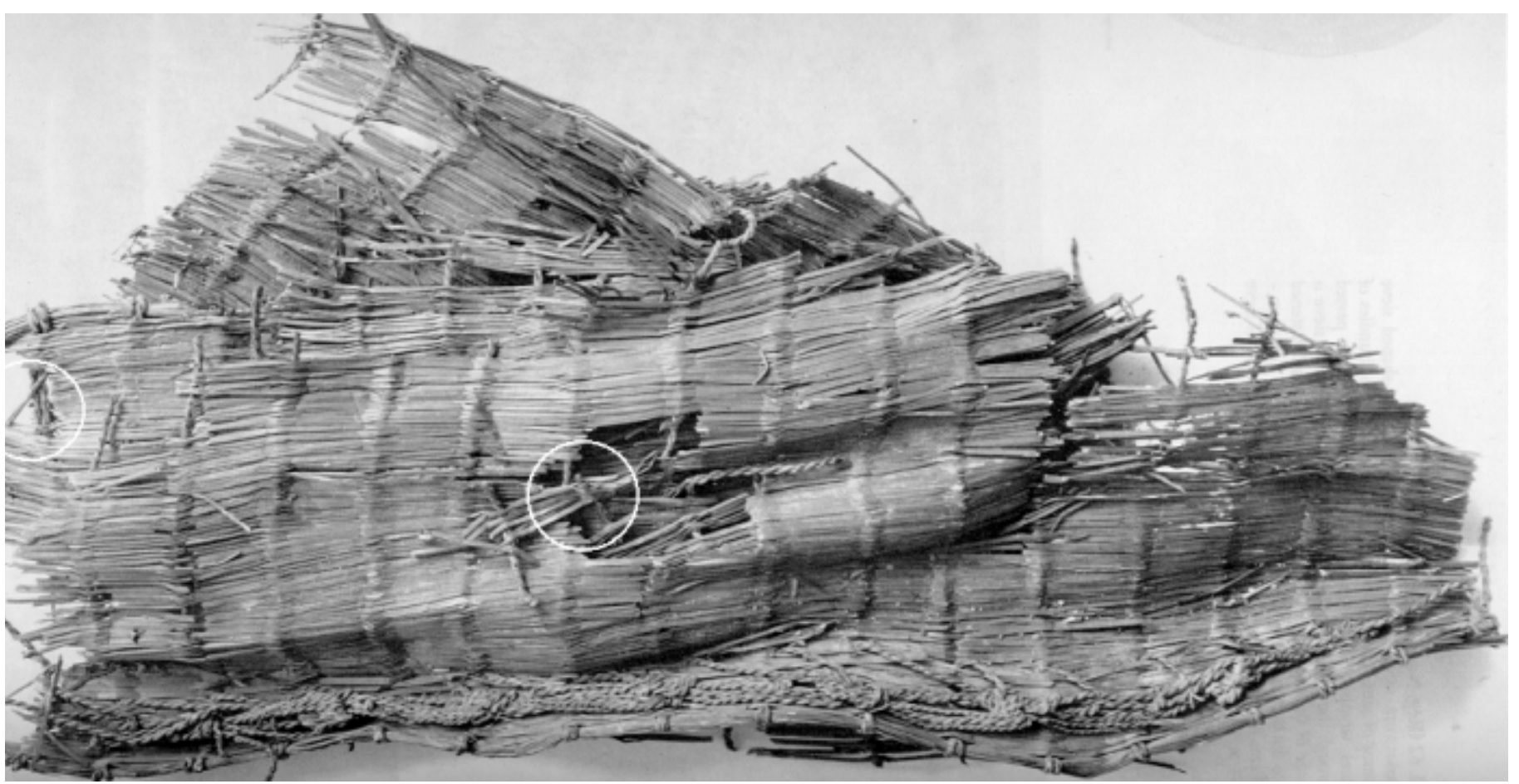

Figure 2 Cave of the Treasure reed mat. The left circle marks the region from which ARP- 213 was taken and the right circle marks the region from which ARP-212 was taken, according to the curator, Ms Osnat Misch-Brandl. (See Bar-Adon 1980:192 for original photo.) 
display good reproducibility, as do ARP-213a (7) and its second check, ARP-213c (9). Thus, the observed spread does not appear to arise from any deficiency in the dating technique. Rather, it seems to be a property of the mat itself, as if different pieces of the mat have different ${ }^{14} \mathrm{C}$ ages.

This surprising result is perhaps not entirely inexplicable. If one accepts the late Chalcolithic setting for the burial of the mat which the excavator, Bar-Adon, claimed, and which the single wood date, I-353 (Table 1), still supports, then the ${ }^{14} \mathrm{C}$ dates presently available on the mat imply that the mat was already centuries old by the time of its burial. This implies that the mat must not have been of mundane use.

This deduction is supported by the nature of the horde of mainly copper objects found buried together with the mat. These objects are generally regarded as temple furnishings, possibly from the nearby Chalcolithic temple at 'En-gedi (Bar-Adon 1980). It is obviously possible that the mat was also part of the temple furnishings - that it was a cult object, rather than for common use as has previously been assumed. If the mat was a religious heirloom and used as a display item only, then it is possible to see how it might have been preserved over many centuries prior to its burial.

Such a view of the mat's purpose lends itself to the idea that the mat may have been repaired over the centuries, and that such repairs may be responsible for the divergent ${ }^{14} \mathrm{C}$ ages from different portions of the mat. But the unique construction method of the mat argues against this idea. The warp of the mat consists of parallel reeds (Figure 2; Bar-Adon 1980). The weft of the mat is a two-ply straw twine. The twine is not woven back and forth between the reeds in the usual way, however. Rather, the reeds are slit at intervals and the twine is passed through these slits (Figure 2). This method of construction does not lend itself easily to spot repairs.

There is another potential explanation of the different dates, however. This is the possibility that the initial object of cult significance, back near the beginning of the Chalcolithic, was not a mat but simply a loose collection of reeds. If this bundle of reeds was kept for centuries before being supplemented by more reeds and fashioned into a mat around $4350 \mathrm{BC}$ (the most probable date of the one weft sample, 6, in Figure 1) most of the ${ }^{14} \mathrm{C}$ data in Figure 1 would be explained.

Such conjectures can only be validated or refuted by additional ${ }^{14} \mathrm{C}$ dates on the mat itself, for which I am hopeful they may provide both incentive and direction. They suggest, for example, that determining whether the straw twine weft is all of the same date might be a fruitful next step. If the twine is all of the same date, then it seems reasonable to conclude that the mat was probably constructed at that date, which the single weft sample (6) reported on here places within a century of $4350 \mathrm{BC}$.

\section{ACKNOWLEDGMENTS}

I would like to thank the Israel Antiquity Authority, particularly Ms Hava Katz, for permission to have the mat redated; the curator, Ms Osnat Misch-Brandl, for her provision of sample material from the mat; the staff and faculty of the University of Arizona AMS radiocarbon lab for their fine work on the samples, their ready willingness to check specific results, and their cooperation in meeting deadlines; R E Taylor for constructive criticism of the original draft of this paper; and Mr Thomas Godfrey for his assistance with locating the right people to enable this project to happen. 


\section{REFERENCES}

Aardsma GE. 1993. A new approach to the chronology of biblical history from Abraham to Samuel. Loda, IL: Aardsma Research \& Publishing. 112 p.

Aardsma GE. 1999. Biblical chronology 101. The Biblical Chronologist 5(4):7-12.

Bar-Adon P. 1980. The Cave of the Treasure. Jerusalem: The Israel Exploration Society. 243 p.

Gonen R. 1992. The Chalcolithic Period. In: Ben-Tor A, editor. The archaeology of ancient Israel. New Haven: Yale University Press. p 40-80.

Stern E, editor. 1993. The new encyclopedia of archaeological excavations in the Holy Lands. New York: Simon \& Schuster.

Stuiver M, Reimer PJ. 1993. Extended ${ }^{14} \mathrm{C}$ data base and revised CALIB $3.0{ }^{14} \mathrm{C}$ age calibration program. $R a$ diocarbon 35(1):215-30. 